\title{
Treatment of chronic osteomyelitis with antibiotic-impregnated polymethyl methacrylate (PMMA) - the Cierny approach: is the second stage necessary?
}

\author{
Noam Bor ${ }^{1,2^{*}}$, Eytan Dujovny ${ }^{1}$, Barak Rinat ${ }^{1}$, Nimrod Rozen ${ }^{1,2}$ and Guy Rubin ${ }^{1,2}$
}

\begin{abstract}
Background: Chronic osteomyelitis is a challenge for orthopedic surgeons. Most patients with osteomyelitis receive two-stage management according to Cierny-Mader. The first stage includes radical debridement and insertion of an antibiotic-impregnated cement spacer (ACS) (beads, rods, nails, or blocks) into the bone defect. The second stage is performed 6-8 weeks later, when the spacer is removed and a cancellous autograft is placed within the bone defect. The possibility of ACS as definitive management for osteomyelitis, avoiding the second stage, is presented.

Methods: Sixteen patients with osteomyelitis received radical debridement and insertion of an ACS in all forms into the bone defect as a definitive management. In 8 patients, the tibia was infected, 4 had femur infection, 2 humerus, 1 fibula, and 1 ankle. The mean age at the time of the first stage of reconstruction was 49 years (range, 13-71 years). According to the Cierny-Mader classification, 1 patient was C-M IA, another was IB, 7 IIIA, 6 IIIB, and 1 was 4A. All B hosts had systemic illnesses. The mean follow-up period was 6 years (1.5-16years).
\end{abstract}

Results: No patient exhibited radiographic evidence of excessive bone loss. Signs of recurrence of osteomyelitis were not noted in any of the patients, and no fractures had occurred by the last follow-up.

Conclusion: Our study suggests that a proportion of patients with planned retention of ACS appear to function well without requiring further surgical intervention, especially in elderly or vulnerable patients.

Keywords: Chronic osteomyelitis, Cierny-Mader, PMMA, Antibiotic cement spacers, Single stage treatment

\section{Introduction}

The treatment of chronic osteomyelitis is a challenging problem for the treating surgeon. The Cierny-Mader (C-M) classification, published in 1984, is based on the anatomy of the bone infection and physiology of the host. Cierny-Mader staging allows stratification of long-bone osteomyelitis and permits the development of comprehensive treatment guidelines for each of the stages [1].

${ }^{*}$ Correspondence: noambor@yahoo.com

1 Orthopedic Department, Emek Medical Center, Afula, Israel

Full list of author information is available at the end of the article
C-M therapy for osteomyelitis is a two-stage approach: Adequate drainage, debridement, and obliteration of dead space are performed at the first stage, while antibiotic impregnated acrylic beads are used to sterilize and temporarily maintain the space. The types of antibiotics are depending on the wound flora which are sensitive to the antibiotic mixed with the cement. Aminoglycosides and vancomycin are common choices for local delivery because of their broad spectrum of activity and thermal resistance [1-15]. Within 4-6weeks, the second operative stage is performed. The beads must be removed and original author(s) and the source, provide a link to the Creative Commons licence, and indicate if changes were made. The images or other third party material in this article are included in the article's Creative Commons licence, unless indicated otherwise in a credit line to the material. If material is not included in the article's Creative Commons licence and your intended use is not permitted by statutory regulation or exceeds the permitted use, you will need to obtain permission directly from the copyright holder. To view a copy of this licence, visit http://creativecommons.org/licenses/by/4.0/. The Creative Commons Public Domain Dedication waiver (http://creativeco mmons.org/publicdomain/zero/1.0/) applies to the data made available in this article, unless otherwise stated in a credit line to the data. 
replaced with a cancellous bone graft $[1,3-5,7,8,10-12$, $15]$.

The delivery of antibiotics locally can be executed by different antibiotic cement spacers (ACSs) in addition to antibiotic-impregnated acrylic beads: cement blocks, or intramedullary custom-made cement rods, all of which need to be removed. Alternatively, antibiotic cement-coated locked intramedullary nails can remain in the medullary canal indefinitely after control of the infection [16].

The purpose of this study was to evaluate the outcome of using ACSs in the form of beads, rods, intramedullary nails, or blocks as definitive management for the treatment of osteomyelitis.

\section{Patients and methods}

We retrospectively reviewed the charts of 27 patients with chronic osteomyelitis who were treated in our institution using the described technique in the last 20 years. Seventeen of the 27 patients received only the first stage of treatment. One of these patients was excluded from the study because of short-term follow-up.

The diagnosis of infection was made according to clinical, laboratory, imaging, microbiological, and pathohistological features. All patients were evaluated by radiographs, either magnetic resonance imaging (MRI) or computerized tomography $(\mathrm{CT})$, and some patients underwent three-phase Tc and indium-labeled leukocyte scintigraphy as part of the preoperative planning. Pain, swelling, and wound drainage were all indicative of infection. The patients were classified physiologically according to the Cierny-Mader criteria as $\mathrm{A}, \mathrm{B}$, or $\mathrm{C}$ hosts. The extent of osteomyelitis was classified anatomically as Types I through IV. The anatomical classification was then combined with the physiological class to designate the clinical stage of the patient $[7,8,12]$. Laboratory tests included white blood cell counts, erythrocyte sedimentation rate (ESR), C-reactive protein (CRP) levels, electrolytes, and infectious disease markers.

In the first and only stage involved in treating the bone infection, all previously inserted hardware was removed, tissue samples were obtained for microbiological analysis, and thorough soft tissue and bone debridement using special burr drills were performed on all patients. If no culture was available, one gram of vancomycin and one gram of gentamycin were mixed into the cement $(40 \mathrm{~g})$. If culture was available, based on knowledge from previous cultures taken from drained sinus for example, the cement was mixed with proper antibiotics the isolated pathogens are sensitive. The most commonly isolated germs were the Staphylococcus aureus and coagulase negative Staphylococcus species. Systemic antibiotics were delivered immediately after surgery. An accurate biological assesment included tissue and fluid cultures for aerobic, anaerobic acid fast bacilli, and fungal organisms. At the time of initial debridement/biopsy, Gram stain results was recorded as well. Initially cefazolin intravenously or broad-spectrum antibiotics were used empirically before the results of sensitivity came out (usually within $48 \mathrm{~h}$ ) and were subsequently modified according to the culture and sensitivity results. After 2 weeks of intravenously treatment, it was changed to oral antibiotics according to the sensitivity results, while CRP, ESR, and routine blood test were regularly monitored. The antibiotic treatment was continued for a minimum of 6 weeks or until the ESR and CRP had returned to normal level.

As early as the third or fourth day after the surgery, all patients were encouraged to walk with partial or either full weight bearing using crutches. At the latest followup all patients were walking normally with full weight bearing.

\section{Results}

We treated 16 patients (13 men and 3 women) with osteomyelitis with a one-stage technique. All patients were treated by the senior author (Table 1). Of these 16 patients, 8 had tibial infections (2 proximal, 2 shaft, and 4 distal), 4 had femur infections (3 distal and 1 shaft), 2 humerus (proximal and distal), 1 fibula (shaft), and 1 ankle. Ten patients had posttraumatic osteomyelitis, two had a history of hematogenous osteomyelitis, and four developed osteomyelitis following elective procedures. The mean age at the time of the first stage of reconstruction was 49 years (range, $13-71$ years).

On the basis of the C-M classification, 1 patient was C-M IA, another was IB, 7 were IIIA, 6 were IIIB, and 1 was $4 \mathrm{~A}$. All B hosts had systemic illnesses.

The delay between the occurrence of bone infection and the treatment ranged from $0.5-25$ years (mean, 5 years).

As for the second and third patients in this series, a second stage was considered, however, failed attempt in removing the antibiotics implants was recorded. In patient No. 2 (Figs. 1, 2 and 3), a surgical trial to remove the intramedullary cement rod and beads from the femoral canal was technically impossible; only a few of the cement beads were removed. In patient No. 3 , only some of the antibiotic cement beads were removed, as they were stuck in thick fibrotic soft tissue.

The various types of antibiotic cement spacers included intramedullary nails in two patients, custom-made cemented rods plus beads in one patient, custom-made cemented rods in four patients, antibiotic beads in one patient, and antibiotic blocks in eight patients. Polymethyl methacrylate (PMMA) bone 
Table 1 Patient demographics

\begin{tabular}{|c|c|c|c|c|c|c|c|c|c|}
\hline Patient & $\begin{array}{l}\text { Age at } \\
\text { surg. } \\
\text { (yrs) } \\
\text { /Gender }\end{array}$ & $\begin{array}{l}\text { Cirny-Madar } \\
\text { Stage }\end{array}$ & $\begin{array}{l}\text { Bone Segment: } \\
\text { PM } \\
\text { D } \\
\text { DM }\end{array}$ & $\begin{array}{l}\text { Etiology of } \\
\text { Infection }\end{array}$ & Microorganism & $\begin{array}{l}\text { Duration } \\
\text { of } \\
\text { infection } \\
\text { (yrs) }\end{array}$ & $\begin{array}{l}\text { Outcome: } \\
\text { Recurrent } \\
\text { infection }\end{array}$ & ACS Type & F-U (yrs) \\
\hline 1 & $M / 46$ & $3 \mathrm{~A}$ & Tibia R - DM & Open \# & NC & 25 & No & Cement block & 14 \\
\hline 2 & $M / 47$ & 3B (Diabetes) & Femur Lt - DM & Open \# - MVA & SA & 18 & No & I.M Rod + beads & 14 \\
\hline 3 & $M / 15$ & $3 \mathrm{~A}$ & Tibia Rt PM & Open \# MVA & PA & 1 & no & Beeds & 16 \\
\hline 4 & $F / 67$ & 3B (Diabetes) & Tibia Rt DM & $\begin{array}{l}\text { Pin tract OM fol- } \\
\text { lowing deformity } \\
\text { correction }\end{array}$ & SA & 8 & no & Cement block & 10 \\
\hline 5 & $M / 13$ & $1 \mathrm{~B}(\mathrm{MMC})$ & Tibia Rt D & $\begin{array}{l}\text { deformity cor- } \\
\text { rectio Int. Fix. } \\
\text { Plating. NU }\end{array}$ & SA & 0.5 & no & Cement rods & 7 \\
\hline 6 & $M / 71$ & 3B (Diabetes) & Tibia Rt PM & $\begin{array}{l}\text { Pin tract OM. \# } \\
\text { tibial Plataou. } \\
\text { Ilizarov EF }\end{array}$ & SA & 1 & no & Cement block & 1.5 \\
\hline 7 & M/65 & 3B (Diabetes) & Tibia Rt DM & \# Open Pilon & NC & 3 & No & Cement Block & 3 \\
\hline 8 & $M / 44$ & $3 \mathrm{~A}$ & Femur Rt DM & $\begin{array}{l}\text { \# Gun shot. } \\
\text { EF } \rightarrow \text { Plating }\end{array}$ & NC & 2 & No & Cement I. M Nail & 2 \\
\hline 9 & $F / 59$ & 3B (U.C) & Tibia Rt D & $\begin{array}{l}\text { Abscess } \rightarrow \\
\text { Bacteremia }\end{array}$ & SM & 0.5 & No & $\begin{array}{l}\text { Two Cement } \\
\text { Rods }\end{array}$ & 7 \\
\hline 10 & $M / 54$ & $1 \mathrm{~A}$ & Femur Rt D & $\begin{array}{l}\text { Septic Knee } \rightarrow \\
\text { bacteremia }\end{array}$ & SA & 1 & No & Cemet I. M Nail & 4 \\
\hline 11 & $M / 67$ & 3B (CA of Colon) & Tibia Rt PM & $\begin{array}{l}\text { ORIF for NU (s/p } \\
\text { HTO for MU post } \\
\text { opened \#) }\end{array}$ & NC & 5 & NO & Cement Block & 5.5 \\
\hline 12 & $M / 22$ & $3 \mathrm{~A}$ & Humerus Lt PM & $\begin{array}{l}\text { \# Per cutaneous } \\
\text { Kirshner wires } \\
\text { OM }\end{array}$ & SA & 3 & No & Cement Block & 3 \\
\hline 13 & M/65 & $3 \mathrm{~A}$ & Ankle Rt & $\begin{array}{l}\text { \# Open Pilon } \rightarrow \\
\text { Ankle fusion (IM } \\
\text { nailing) }\end{array}$ & PA & 1 & No & $\begin{array}{l}\text { Cemented } \\
\text { Ilizarov Rod }\end{array}$ & 2.5 \\
\hline 14 & $M / 56$ & $4 \mathrm{~A}$ & Fibula LT D & $\begin{array}{l}\text { \# Conservative } \\
\text { treatment }\end{array}$ & SA & 5 & No & Cement Rod & 2 \\
\hline 15 & $M / 21$ & $3 \mathrm{~A}$ & Humerus Rt D & $\begin{array}{l}\text { \# Open Fracture } \\
\text { (ORIF) }\end{array}$ & $P R$ & 3 & No & Cement Block & 1.5 \\
\hline 16 & $F / 64$ & $3 \mathrm{~A}$ & Femur Rt D & $\begin{array}{l}\text { s/p Varus Oste- } \\
\text { otomy - Plating }\end{array}$ & SA & 0.5 & No & Cement Block & 7 \\
\hline
\end{tabular}

$M$ male, $F$ female, UC ulcerative colitis, $C A$ cancer, $P M$ proximal metaphysis, $D$ diaphysis, DM distal metaphysis, $M V A$ motor vheicle accident, $O M$ osteomyelitis, $M M C$ myelomeningocele, EF external fixation, I. M intramedullary, ORIF open reduction and external fixation, NU nonunion, $M U$ malunion, $H T O$ high tibial osteotomy, $S A$ Staphylococcus Aureus, PA Pseudomonas Aeruginosa, SM Serratia Marcescens, PR Provedencia Rettgeri, NC not cultured

cement (Smith \& Nephew, TN, USA) was used in all patients. Additional sensitive antibiotics were added to the powder before mixing the powder and the liquid.

A satisfactory result was defined as no drainage or open wound and no clinical, radiographic or laboratory evidence of infection. At the latest follow-up, ranging from 1.5 to 16 years (average, 6 years), none of the patients exhibited radiographic evidence of excessive bone loss, signs of recurrence of osteomyelitis, or fractures. All patients had no drainage, pain or signs of inflammation, and all laboratory parameters were normal.

\section{Discussion}

Our study on 16 patients proves the theory that the second stage of the Cierny-Mader approach to chronic osteomyelitis, in certain circumstances, can be avoided, and no complications are due to come out by retaining the ACA for long standing.

In 1984, Cierny and Mader published a unique classification system for chronic osteomyelitis, taking into account the importance of the immune competency and physiological ability of the host to affect healing, and the anatomic nature of the disease, introducing the two-stage technique [1]. 

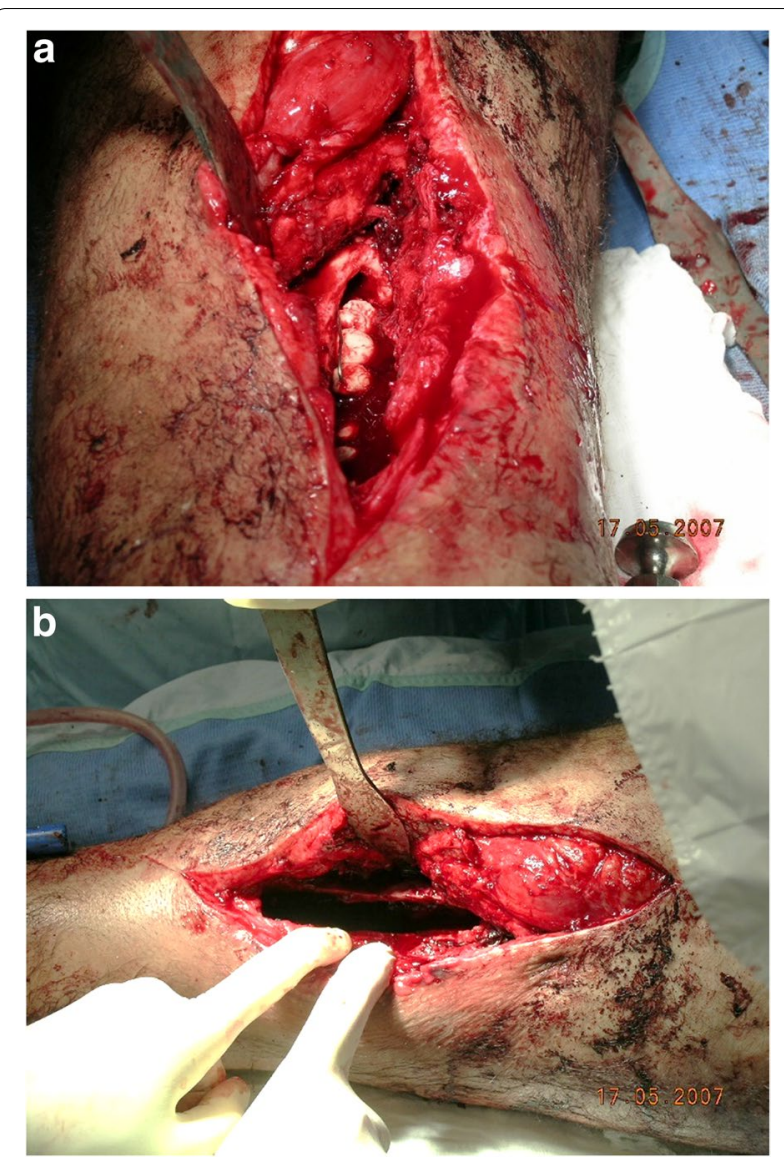

Fig. 1 a, b Cierny $3 \mathrm{~A}$ - femur/chronic OM for 8 years; operation year: 2007; debridement and insertion of PMMA - AB and antibiotic rod
The technique has the following disadvantages: The polymethyl methacrylate (ACS) is required to be removed. Obviously, there are independent medical and surgical risks by performing an additional operation, as well as costs both to the patient and health care system (24). ThePMMA can also offer a substrate for bacterial colonization when the release of antibiotics declines over time and finally becomes ineffective. However, the main advantage of this technique is thehigh local antibiotics concentrations achieved, the risk of systemic toxicity is minimized, the long-term exposure to intravenous antibiotics delivery, which is strongly related to the emerging threat of antibiotic resistance, is avoided [17].

Therefore, many surgeons were looking for effective one-stage procedure, using different antibiotic delivery systems which are not required to be removed, antibioticimpregnated bioabsorbable bone substitutes. New biomaterials were introduced: Collagen fleece, an effective triphasic antibiotic release, and polyesters which offer a slower breakdown and some evidence of intracellular action [18]. Calcium-based carriers, including plaster of Paris, calcium sulfate [19], and calcium hydroxyapatite, allow tissue and bone ingrowth as they degrade. Insertion of tobramycin-impregnated calcium sulfate pellets recorded to be effective in a group of 12 skeletally immature patients with chronic osteomyelitis of the long bones [20]. Another recent study showed one-stage treatment of chronic osteomyelitis with bioactive glass S53P4 [21]. Other potential delivery systems are polyanhydrides, amylose starch, and composite carriers [18, 19].
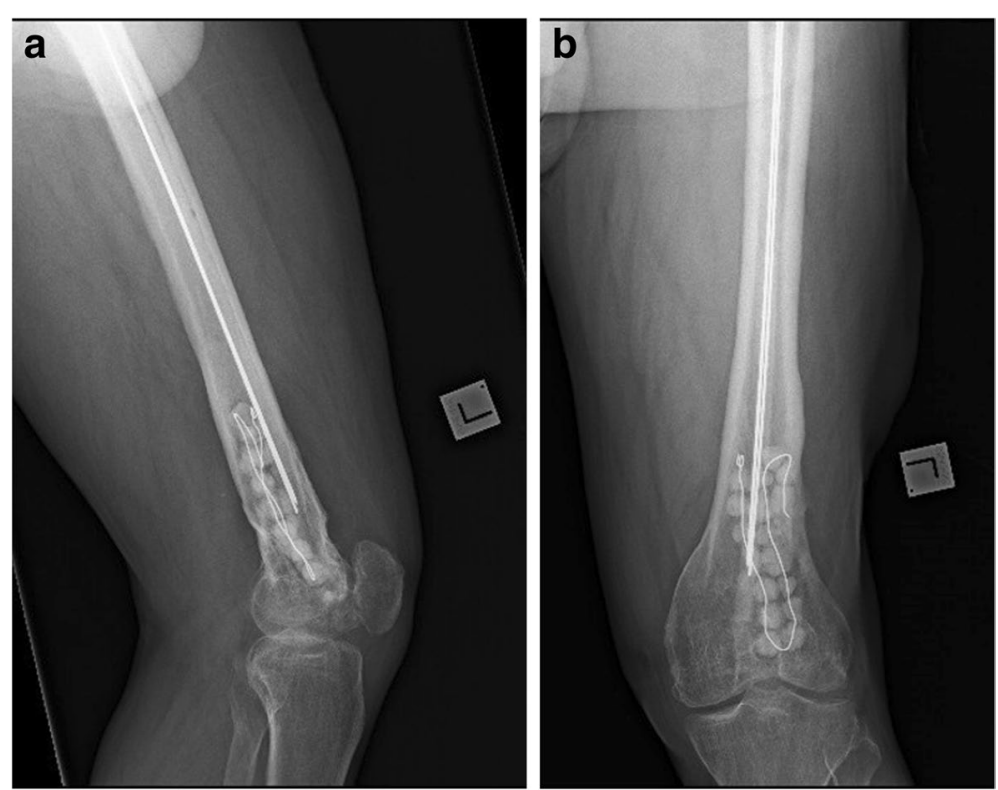

Fig. 2 a, b Eleven-year follow-up (retained antibiotic beads and cement rods) 


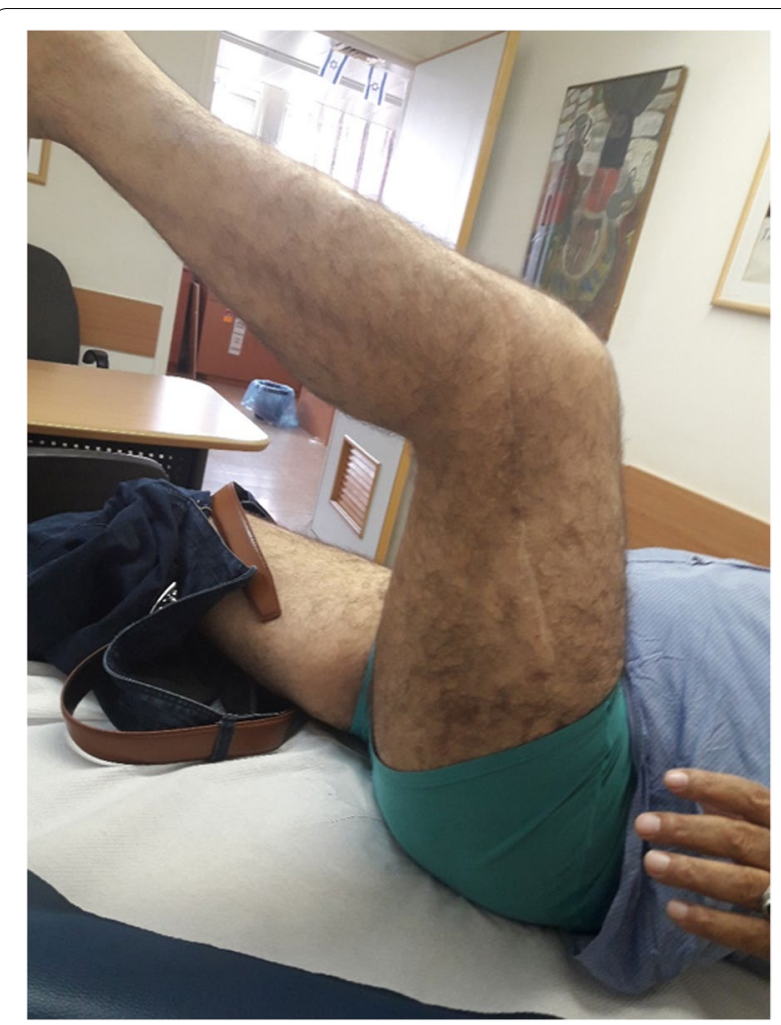

Fig. 3 Eleven-year follow-up - no signs of infection; cemented rod and beads not removed

The various biocompatible and bioabsorbable technologies are especially useful, if a planned secondary procedure for re-instrumentation, bone grafting, or soft-tissue reconstruction are not required. However, the biodegradable products have their drawbacks: (1) Not strong enough as load-bearing spacers; (2) Intrinsic chemical intolerances preventing the product(s) from hardening limiting the amount of mixing up antibiotics. (3) Inflammatory byproducts released during their degradation creating eventually wound seromas in as many as $20-28 \%$ of cases [22].

None of the patients in our study received secondstage reconstruction, they all, except for one, were of type 1 through 3 according to the Cierny-Mader classification, and retained the ACS. Following the first stage of treatment, all bone segments were stable enough, the mechanical integrity of the remaining bony segments in patients with Cierny-Mader type III was satisfactory, therefore, there was no need to perform any stabilization procedure or reinforcement of bone segments at a second stage.

Our method is not applicable in patients with CiernyMader type IV, where a considerable amount of bone segment is required to be removed during the first stage of treatment, major reconstruction is needed, performed during the second stage. Therefore, these patients must be treated according to the traditionally 2-stage treatment recommended by Cierny-Mader.

The only patient in our study with Cierny Mader type $\mathrm{IV}$, the fibula was involved, a non-weight bearing bone, therefore a second stage with major defect reconstruction was not required. None of the ACS drawbacks described above were noted during long-term follow-up. None of the patients exhibited any sign of osteomyelitis recurrence.

The decision to avoid the second operative stage was also supported and encouraged by our favorable experience with the earlier two patients in this group, in whom a trial to remove the ACS failed. Three years of follow-up on these patients resulted in no complications.

To the best of our knowledge, only two reports referring to the long-term use of ACSs in patients with osteomyelitis in long bones are available: In a study by $\mathrm{Xu}$-Sheng Qiu et al. [23], cement spacers were not removed following treatment for chronic osteomyelitis in eight patients (7 tibias, 1 calcaneus). After a mean follow-up period of 2 years, no signs of recurrence of osteomyelitis were noted in any of the patients. In another recent study by Frenando et al. [24], reporting on 37 patients who did not undergo antibiotic-impregnated PMMA bead removal, at long-term follow-up (range 6 months-5 years), there were no wound complications or recurrent infections.

Paley and Herzenberg treated infected intramedullary canals with antibiotic impregnated custommade cement rods in nine patients. In one 70-year-old patient, the rod was not removed, and no signs of recurrent infection were noted 38 months later [13]. In our study, the follow-up was longer, and various types of cement spacers were used in comparison to other literature reports.

Our decision to avoid the second-stage operation according to Cierny-Mader is also based on the vast experience of joint replacement surgeons and the related literature regarding the use of PMMA bone cement. The use of cemented femoral stems is safe, increasing with the aging population for both elective and nonelective hip arthroplasty especially [25]. Choi et al. reported 18 patients with periprosthetic joint infection (11 hips, 7 knees) treated with retained prosthetic articulating spacers. At an average of 43.8 months (range, $13-78$ months) of follow-up, no cement spacer-related complications were noticed [26].

Ferrao et al. [27] reported using ACSs as definitive management for postoperative ankle infection. At a 20.1month (range, 6 to 62 months) follow-up, seven patients still retained their cement spacer with no complications. 
According to our results, we believe that a second operation with all its risks can be avoided, especially in elderly or vulnerable host $\mathrm{B}$ or $\mathrm{C}$ patients. The use of absorbable biomaterials has its downsides, as reported above; in addition, they are expensive and not always available in the developing world.

\section{Acknowledgements}

Not applicable.

\section{Authors' contributions}

NB - Conception and design, acquisition of data, analysis, and interpretation of data, drafting the article, final approval. ED - Analysis and interpretation of data, revising the article, final approval. BR - Acquisition of data, Revising the article, final approval. NR - Conception and design, Acquisition of data, revising the article, final approval. GR - Conception and design, Acquisition of data, revising the article, final approval. All authors read and approved the final manuscript.

\section{Funding}

The study has no founding.

\section{Availability of data and materials}

All data generated or analysed during this study are included in this published article.

\section{Declarations}

\section{Ethics approval and consent to participate}

The study was approved by the Emek medical centercal ethical committee. Written informed consent was obtained from the patient's legal guardian(s) and all patients. All methods were performed in accordance with the relevant guidelines and regulations.

\section{Consent for publication}

Written informed consent was obtained from the patient's legal guardian(s) for publication of this paper and any accompanying images. A copy of the written consent is available for review by the Editor-in-Chief of this journal. Consent for the publication of identifying images or other personal or clinical details of participants that compromise anonymity - Written informed consent was obtained from the patient's legal guardian(s).

\section{Competing interests}

Not applicable.

\section{Author details}

'Orthopedic Department, Emek Medical Center, Afula, Israel. ${ }^{2}$ Faculty of Medicine, Technion, Haifa, Israel.

Received: 24 September 2021 Accepted: 20 December 2021

Published online: 06 January 2022

\section{References}

1. Cierny G, Mader JT. Adult chronic osteomyelitis. Orthopedics. 1984;7(10):1557-64.

2. Bharti A, Saroj UK, Kumar V, Kumar S, Omar BJ. A simple method for fashioning an antibiotic impregnated cemented rod for intramedullary placement in infected non-union of long bones. J Clin Orthop Trauma. 2016;7(Suppl 2):171-6.

3. Chan YS, Ueng SW, Wang CJ, Lee SS, Chen CY, Shin CH. Antibioticimpregnated autogenic cancellous bone grafting is an effective and safe method for the management of small infected tibial defects: a comparison study. J Trauma. 2000;48(2):246-55.

4. Cierny G 3rd. Infected tibial nonunions (1981-1995). The evolution of change. Clin Orthop Relat Res. 1999;(360):97-105.
5. Cierny $\mathrm{G}$ 3rd. Surgical treatment of osteomyelitis. Plast Reconstr Surg. 2011;127(Suppl 1):190S-204S.

6. Cierny G 3rd, DiPasquale D. Treatment of chronic infection. J Am Acad Orthop Surg. 2006;14(10):S105-10.

7. Cierny G 3rd, Mader JT, Penninck JJ. A clinical staging system for adult osteomyelitis. Contemp Orthop. 1985;10:17-37.

8. Cierny $\mathrm{G}$ 3rd, Mader JT, Penninck JJ. A clinical staging system for adult osteomyelitis. Clin Orthop Relat Res. 2003;414:7-24.

9. Forsberg JA, Potter BK, Cierny G 3rd, Webb L. Diagnosis and management of chronic infection. J Am Acad Orthop Surg. 2011;19(Suppl 1):S8-S19.

10. Kinik H, Karaduman M. Cierny-Mader type III chronic osteomyelitis: the results of patients treated with debridement, irrigation, vancomycin beads and systemic antibiotics. Int Orthop. 2008;32(4):551-8.

11. Mader JT, Cripps MW, Calhoun JH. Adult posttraumatic osteomyelitis of the tibia. Clin Orthop Relat Res. 1999;360:14-21.

12. Mader JT, Shirtliff M, Calhoun JH. Staging and staging application in osteomyelitis. Clin Infect Dis. 1997;25(6):1303-9.

13. Paley D, Herzenberg JE. Intramedullary infections treated with antibiotic cement rods: preliminary results in nine cases. J Orthop Trauma. 2002;16(10):723-9.

14. Tetsworth K, Cierny G 3rd. Osteomyelitis debridement techniques. Clin Orthop Relat Res. 1999;360:87-96.

15. Ziran BH, Rao N, Hall RA. A dedicated team approach enhances outcomes of osteomyelitis treatment. Clin Orthop Relat Res. 2003:414:31-6.

16. Thonse R, Conway JD. Antibiotic cement-coated nails for the treatment of infected nonunions and segmental bone defects. J Bone Joint Surg Am. 2008:90(Suppl 4):163-74.

17. Heijink A, Yaszemski MJ, Patel R, Rouse MS, Lewallen DG, Hanssen AD. Local antibiotic delivery with OsteoSet, DBX, and Collagraft. Clin Orthop Relat Res. 2006:451:29-33.

18. Sanders J, Mauffrey C. Long bone osteomyelitis in adults: fundamental concepts and current techniques. Orthopedics. 2013;36(5):368-75.

19. Qin C, Xu L, Liao J, Fang J, Hu Y. Management of Osteomyelitis-Induced Massive Tibial Bone Defect by Monolateral external fixator combined with antibiotics-impregnated calcium Sulphate: a retrospective study. Biomed Res Int. 2018;2018:9070216.

20. Andreacchio A, Alberghina F, Paonessa M, Cravino M, De Rosa V, Canavese F. Tobramycin-impregnated calcium sulfate pellets for the treatment of chronic osteomyelitis in children and adolescents. J Pediatr Orthop B. 2019;28(3):189-95.

21. Geurts J, van Vugt T, Thijssen E, Arts JJ. Cost-Effectiveness Study of OneStage Treatment of Chronic Osteomyelitis with Bioactive Glass S53P4. Materials (Basel). 2019;12(19):3209.

22. McKee MD, Wild LM, Schemitsch EH, Waddell JP. The use of an antibioticimpregnated, osteoconductive, bioabsorbable bone substitute in the treatment of infected long bone defects: early results of a prospective trial. J Orthop Trauma. 2002;16(9):622-7.

23. Qiu XS, Zheng X, Shi HF, Zhu YC, Guo X, Mao HJ, et al. Antibiotic-impregnated cement spacer as definitive management for osteomyelitis. BMC Musculoskelet Disord. 2015;16:254.

24. Fernando N, Werner S, Elhaddad M, Davies J, Firoozabadi R. Do antibiotic beads need to be removed? Arch Bone Joint Surg. 2020;8(4):502-5.

25. Scanelli JA, Reiser GR, Sloboda JF, Moskal JT. Cemented femoral component use in hip arthroplasty. J Am Acad Orthop Surg. 2019;27(4):119-27.

26. Choi HR, Freiberg AA, Malchau H, Rubash HE, Kwon YM. The fate of unplanned retention of prosthetic articulating spacers for infected total hip and total knee arthroplasty. J Arthroplast. 2014;29(4):690-3.

27. Ferrao P, Myerson MS, Schuberth JM, McCourt MJ. Cement spacer as definitive management for postoperative ankle infection. Foot Ankle Int. 2012;33(3):173-8.

\section{Publisher's Note}

Springer Nature remains neutral with regard to jurisdictional claims in published maps and institutional affiliations. 